The manuscript below is the original draft of an article has been accepted for publication in the Journal of Sustainable Finance and Investment, published by Taylor \& Francis. The publication will have the following reference.

Dimmelmeier, Andreas. „Sustainable Finance as a Contested Concept: Tracing the Evolution of Five Frames Between 1998 and 2018“. Journal of Sustainable Finance \& Investment, o. J. https://doi.org/10.1080/20430795.2021.1937916.

\title{
Sustainable Finance as a Contested Concept: Tracing the Evolution of Five Frames Between 1998 and 2018
}

\author{
$\underline{\text { Andreas Dimmelmeier }}$
}

Sustainable finance has received increasing attention over the last years. Nonetheless, the meaning of the term remains ambiguous. This article approaches this ambiguity by understanding sustainable finance as a contested concept, whose meaning has been subject to varying interpretations by different actors. To map these interpretations, the article offers an inductive analysis of the network of actors that concern themselves with sustainable finance. Inside of this network actors offer competing interpretations of sustainable finance which can be conceptualised as frames. Using network analysis and interviews I identify five frames that are present in three periods between 1998 and 2018. Distinct communities advance a Socially Responsible Investment frame, a risks and opportunities frame, a climate finance frame, a critical frame and an integrated frame that tries to bring the different actors together. Describing the emergence of these frames, their position in the network and their relations to each other can add to our understanding of sustainable finance as it complements existing authoritative classifications and histories of the topic.

Keywords: sustainable finance, framing, contested concepts, networks, history

Sustainable finance has enjoyed a marked increase in attention over the past couple of years.

One indication of the growing importance of sustainable finance is its increasing financial weight. Albeit still accounting for a fraction of global bonds, the market for instruments specifically marked as green increased fivefold between 2016 and 2020. As a result, in December 2020, there were US \$ 1 trillion outstanding green bonds (Jones 2020). In addition, funds that are governed according to Environmental, Social and Governance (ESG) criteria 
have attracted record inflows of US \$ 71 billion in 2020 pushing the amount of assets that are managed according to these criteria over the US \$ 1 trillion threshold (Riding 2020).

Another indication of the increasing salience of sustainable finance is the proliferation of political and regulatory initiatives. National governments and regulators as well as transnational fora like the G20 and International Organisations (IOs) like the International Monetary Fund (IMF) have started to devote some of their resources and publishing activities to the topic (e.g. IMF 2019; 2020, G20 Green Finance Study Group 2017). In addition, the Network for Greening the Financial System (NGFS), has over its short three years of existence already welcomed 83 central banks and regulators from five continents ${ }^{1}$, as well as published its first reports and recommendations (e.g. NGFS 2019).

Other prominent developments include the work of the Financial Stability Board's Task force on climate-related disclosures (FSB TCFD) framework for reporting by companies and financial institutions (since 2015), the adoption of a 35-point plan on green credit by the Chinese regulatory commission (2016), the work of the G20's green finance study group (2015-2018) and the European Commission's (EC) action plan on sustainable finance (EC 2018). Besides these high-level initiatives, other national bodies have also accelerated their actions on sustainable finance. A 2018 UNEP report found 300 policy and regulatory measures in 54 jurisdictions, a $100 \%$ increase from 2013 (Zadek and Robins 2018: 25). Furthermore, increased knowledge production of policy proposals, metrics and risk assessment tools has created an entire cottage industry of commercial data providers, think tanks and Non-Governmental Organisations (NGOs).

While some observers contended that the preoccupation with sustainable finance was a boom-time luxury that would recede in the event of a crisis, it appears that the developments

\footnotetext{
${ }^{1}$ As of December 2020, membership notably includes the US Federal Reserve.
} 
during the ongoing Covid-19 pandemic have so far proved them wrong. During the pandemic sustainability-linked funds appear to have financially outperformed traditional investments (Riding 2020). Another indication of the perseverance of sustainable finance is that the EU has linked its recovery funding to its new sustainable finance taxonomy (EC 2020).

The above-described developments suggests that something labelled 'sustainable finance' has established itself in multiple institutional and geographical sites across the world's financial, economic and political systems. This notwithstanding, the meaning of the term sustainable finance remains ambiguous. When reviewing the different initiatives and approaches, an array of possible answers to the question what sustainable finance means appear. One might interpret sustainable finance as an equivalent or an evolution from Socially Responsible Investment (SRI) as eurosif, a trade association, has suggested (Micilotta et al. 2016: 9). Alternatively, it can be framed in terms of Environmental, Social and Governance (ESG) risks. The issuance of green bonds or green central banking are also contenders when looking for a definition. Lastly, a more cynical view might interpret the term as a mere exercise in 'greenwashing.'

In the policy debate the ambiguity of the term sustainable finance has amongst other been addressed through typologies that break it down into sub-concepts like green finance, low carbon finance and socio-environmental finance (Forstater and Zhang 2016: 11). Taking a more critical stance, an academic contribution by Haigh (2012) suggests that sustainable finance is an "empty signifier" (see also Eccles 2013). Accordingly, stakeholders like financial institutions, policymakers and civil society utilise the term in accordance with their interests and ideas. Historical analyses have, meanwhile, emphasised that the ambiguity stems from different approaches which emerged at different points in time (e.g. Robins and McDaniels 2016; Schoenmaker 2017, Sparkes 2002). 
In this article, I complement and integrate these analyses by inductively constructing a typology that maps the different interpretations of sustainable finance over time. Rather than treating the term as an empty signifier, I suggest that sustainable finance is better understood as a 'contested concept' whose meaning is debated, yet not completely open to interpretation. Thus, its meaning shifts with changes in the configurations of actors that refer to sustainable finance. To map the different meanings, I utilise the concept of framing. This is operationalised through a multi-method design consisting of network analysis, text analysis and semi-structured interviews. Said multi-method design helps map the evolution of actors which refer to sustainable finance. Importantly, in terms of the underlying textual data, I depart from earlier inductive analyses that have focused on academic publications and, instead, introduce an original dataset of policy literature.

Through the construction of information networks for the period between 1998 and 2018, I establish the relations between the different actors and between the frames they utilise. Understanding which actors frame sustainable finance in which ways elucidates the contesting interpretations of the concept. Mapping the interests, ideas and practices of the actors, as well as the cleavages that have occurred between them, can provide further context for understanding current developments and debates in sustainable finance.

The article is divided into six sections. First, I revisit some of the academic and practitioner literature on the evolution of sustainable finance. Then, I describe the theoretical edifice of contested concepts, frames and networks. The third section introduces the methods and data sources, while the fourth describes the findings. It divides the timeframe between 1998 and 2018 into three periods. Whereas the fifth section summarises and discusses the findings, the sixth and final one concludes the article. 


\section{Ordering Sustainable Finance: Classifications, Literature Reviews and Histories}

To map the different interpretations of sustainable finance, academics and practitioners have turned to classification tables, reviews of the academic literature and historical analyses. Classification tables offer a conceptual differentiation. The relevance of such tables often comes from the authority of the institutions that create them. One example is a table developed by the United Nations Environment Program's Inquiry into a sustainable financial system (UNEP Inquiry) which has among other been used by the European Commission's High-Level Expert Group on sustainable finance (2017: 12). This categorisation separates the sustainability part of sustainable finance into an environmental, a social, an economic and a governance dimension (Forstater and Zhang 2016: 11). The IMF for its part has adopted both a classification table that reproduces the widely used separation between the Environmental, Social and Governance aspects (ESG) of sustainable finance, as well as another that has differences in asset classes as its main dimension (IMF 2019: 82, 86).

Other prominent classification systems place investment approaches on a continuum that records their degree of sustainability or 'responsibleness.' In these representations traditional finance's singular concern with financial returns is routinely placed at one end of the spectrum, whereas impact investing that foregrounds non-financial considerations occupies the other (e.g. Maulemans 2018: 8).

Classification tables offer a clear categorisation of the approaches that are associated with sustainable finance. Nonetheless, they are somewhat static and ahistorical tools as novel interpretations that do not fit the chosen dimensions cannot be easily incorporated. Perhaps more importantly, as they are aimed at conveying information to practitioners, classification tables are often based on implicit knowledge. Thus, categorisations that are built on firmer empirical grounds could help assess the validity of such typological exercises. 
Systematic literature reviews, by contrast, are based on clearly identifiable datasets. Yet the cross-disciplinary nature of studies on sustainable finance has made comprehensive literature reviews a complex affair. The literature reviews by Eccles (2013) and Rezende et al. (2016) address this issue of interdisciplinarity by sampling from the Journal of Sustainable Finance and Investment, which is specifically focused on sustainable finance and invites contributions from "conventionally unrelated fields" (cf. JSF\&I 2020). Through examining and coding 64 articles, Eccles (2013: 290ff) finds an omission of a concrete discussion of the concept of sustainability. He concludes that the sustainable in sustainable finance can, indeed, be described as an empty signifier. Rezende et al. (2016), meanwhile, examine amongst other the geographies, sectors and topics as well as the methods of 113 articles on sustainable finance. In their inductive analysis, they find a diverse set of topics including research on capital markets, sustainability indicators and micro finance. Yet the literature is also biased towards studying developed countries and the private sector. In terms of methodology, they find a bias towards case studies and the relative absence of studies that take extended time periods into account.

Literature reviews offer a methodologically rigorous and empirics-based understanding of both the different facets of sustainable finance as well as of the conspicuous absences. Yet the study of the academic literature is always an indirect way of assessing how the 'actors on the ground' understand and practice sustainable finance.

Historical analyses concern themselves with such actors and utilise a variety of data sources and methods including text analysis, interviews and statistical datasets. Accounts on how modern finance became linked to issues of ethics and responsibility trace the first connections back as early as 1948 (Sparkes 2002: 27ff). Over the years, researchers have observed the growth of sustainable finance in terms of organisations involved, money invested (e.g. Crifo et al. 2019) and coverage in the news (Dumas and Louche 2016). When recounting 
the history of sustainable finance across various geographies, they have observed a shift from Socially Responsible Investment (SRI) to a more risk-based understanding (e.g. Robins and McDaniels 2016, Dumas and Louche 2016, Schoenmaker 2017).

Historical treatments offer a nuanced, empirics-based and dynamic understanding of sustainable finance. Yet some of the existing assessments display a tendency towards linear and teleological accounts that suggest a continuous progression. One volume, for example, has the extended title "Responsible investment: A global revolution" (Sparkes 2002), which can be read as an indication of the transformative potential of the practice. Schoenmaker $(2017,30 \mathrm{ff})$ also implies a normative progression by speaking of the transition from "sustainable finance 1.0 " to "sustainable finance 3.0". While such assessments provide valuable descriptions of the continuities and changes over time, they also risk downplaying the contestations between different communities of actors.

\section{Towards an Alternative Typology: Contested Concepts, Frames and Expert Networks}

\section{Ambiguity as Concept Contestation}

Instead of looking for a 'true' definition of sustainable finance or a definitive typology that can be proposed by authoritative institutions, I map the various meanings of the term inductively by looking at the actors that refer to sustainable finance. Importantly, this approach is distinct from both treating sustainable finance as an empty signifier as well as from the notion of progress towards an ever more 'real sustainability.'

To convey that ambiguity is an integral component rather than an aberration for sustainable finance, I treat the term as a 'contested concept.' The notion of an 'essentially contested concept" was introduced by the philosopher Gallie (1955) to describe a situation in which actors use a concept for "different (...) though not altogether unrelated functions" (Gallie 
1955: 168). One important characteristic of a contested concept is that, while ambiguous, it retains a core meaning that prevents actors from using it indeterminably. Gallie points to the examples of concepts like art or democracy, which while having a rough core meaning, nonetheless have been subject to varying interpretations by different actors in different time periods. Notably, sustainable development has also been described as a contested concept. Scholars have referred to Gallie's work to highlight that sustainable development is a political concept and that attempts to establish its true meaning analytically are misguided (Conelly 2007, Jacobs 1999). It has also been noted that a single dimension is insufficient to understand the variations of sustainable development (Conelly 2007: 261).

\section{Concept Contestation as Framing}

To identify the different interpretations of sustainable finance, I use the concept of framing. This allows for an inductive analysis and does not require variations to be placed on a single dimension. This notwithstanding, the concept of framing is sufficiently coherent to ensure that the interpretations remain commensurable.

Framing has been defined as individuals' response to the question "What is it that's going on here?" (Goffman 1974: 8), social movement actors' construction of "a shared understanding of a problematic situation that they define as being in need of change" (Benford and Snow 2000: 615) or, alternatively, as the selection and making salient of aspects of a perceived reality (Entman 1993: 52). A commonality of these definitions is that they emphasise frames' function as uncertainty-reduction devices which enable actors to understand and transform their environment. As such, the concept of framing connects well with the ambiguous situation that actors face when dealing with sustainable finance.

In terms of the empirical operationalisation of frame analysis, some authors have developed categorisations of frames (e.g. Benford and Snow 2000: 615ff), while others adopt an inductive approach (e.g. Ban 2015; Hjerpe and Buhr 2014). As the established protocols are 
more attuned to the study of social movements than to the more elite interactions in sustainable finance, I follow an inductive approach.

\section{Expert Networks as the Sites Where Framing Takes Place}

So far, I have suggested that sustainable finance can be understood as a contested concept. Meanwhile, the contesting positions themselves can be found inductively by looking at the frames that actors put forward. This approach requires a method for delineating who can be considered an actor. In addition, we must be able to source data that records how the actors interpret sustainable finance. Finally, the investigation should be dynamic to integrate observations about changes in the relative importance of frames.

To address these demands, I suggest that it is useful to think about the population of actors that refer to sustainable finance as an expert network. Such networks have been studied by an emerging literature in sociology that emphasises the importance of individuals and organisations when defining and controlling 'issues' in ambiguous - and often transnational environments (Henriksen and Seabrooke 2016). Examples of issues that feature the contestation of concepts are sustainability accounting (Thistlethwaite and Paterson 2016) and the emergence of emission trading venues (Paterson et al. 2014). Importantly, conceptualising an issue in terms of an expert network allows for the incorporation of different actor types including private and public sector organisations, Civil Society Organisations (CSOs) and IOs.

The analysis of expert networks is often geared to finding out who (i.e. which people or organisations) is in control of a particular issue. When understanding sustainable finance as a contested concept this analysis has, however, to be complemented with a focus on what (i.e. which frames) is promoted by the actors. To reflect this different emphasis, I focus on copublication networks rather than on professional or institutional collaborations. While the next 
section will elaborate on the methods in more detail, the rationale behind this is that joint knowledge production is a sign of epistemic agreement. Proximity in the analysis of citation networks has, for example, been used to detect shared research clusters or schools of thought (e.g. Bearman and Shwed 2010, Seabrooke and Young 2017).

\section{Mapping Frames Through Network Analysis and Interviews}

\section{Network Analysis: Terms and Methods}

In its most basic form, a network describes a system by looking at its individual parts and their interaction. Identifying patterns in the interactions between the individual parts can increase our understanding of the behaviour of the system as a whole (Newman 2010: 1-2). A common feature of all networks is that one must specify the parts of the system and the nature of their interaction. In other words, the nodes (actors) and the edges (links) have to be defined. As I am interested in the knowledge production of actors that refer to sustainable finance, I define the nodes as texts that concern themselves with this issue. The texts are linked if they have one or more joint authors, reflecting the assumption that experts will display a certain consistency in their framing. Furthermore, I attribute the texts to the organisations that publish them to provide a more high-level overview of the situatedness of the frames.

Before starting to link the texts, one must, however, define the population of sources. This notion of demarcating what is inside the system is also known as boundary specification. In the absence of agreed on lists indicating who can be considered a sustainable finance actor, I adopt the so called 'nominalist' strategy where boundaries are defined by the research question (cf. Rinscheid 2015: 44). I first apply a system definition strategy that comes from the study of elite networks in order to delineate the organisations that are included (cf. Knoke 1993). 
Subsequently, I use a topic-matching approach as used in the study of information networks to delineate which of the texts that are published by these organisations are included.

To convey the structure of the network, I rely on visual representations, where the representation puts strongly connected nodes next to each other and the most connected nodes at the centre of the graph. In addition, there are two statistical network measures and one clustering algorithm that feature in the analysis. As a first indication for determining important nodes, I use the concept of degree centrality, which is defined as the sum of links that a node possesses.

The second network statistic is betweenness centrality This measure assigns high values to nodes that link parts of the network that would have been disconnected otherwise. In social networks and information networks, high betweenness centrality scores identify nodes that aggregate information and occupy positions that bridge otherwise separate communities (cf. Borgatti et al. 2013: 185ff; Burt 1992; Seabrooke 2014). Identifying nodes with high betweenness centrality can reveal individuals and texts that integrate information from different sources.

Lastly, I utilise the Newman-Girvan algorithm to identify clusters. This algorithm is based on the concept of betweenness centrality. It iteratively removes edges with high betweenness centrality to detect the clusters that have many links among themselves but are only connected to other parts of the network through these high centrality edges (Girvan and Newman, 2002; for an application see Rinscheid 2015). ${ }^{2}$ Identifying such clusters is especially relevant for frame analysis as clusters in social networks are often characterised by shared ideas (Borgatti et al. 2013: 193).

\footnotetext{
${ }^{2}$ Technical appendices and calculations are recorded on a shared database. Access can be requested via the author.
} 


\section{Network Analysis: Original Dataset}

I established the dataset by delineating the boundaries of the network of sustainable finance actors in two steps. First, I employed the so called reputational and the relational method to delimit which organisations can be considered actors that produce knowledge on sustainable finance. The reputational method relies on expert judgements to determine the members of the network. These judgements can either come from outside observers like academics and journalists or from actors in the network themselves. The relational method, meanwhile, starts from a set of actors that have been found with the use of another method and, subsequently, includes those who cooperate with these actors as new members (Knoke 1993: 30).

Accordingly, I sampled organisations by looking at scholarship (e.g. Clapp and Thistlethwaite 2012; Hoffmann 2011; MacLeod and Park 2011; Newell and Paterson 2010; Thistlethwaite 2011; 2015), newspaper articles ${ }^{3}$ and 'community mapping reports' produced by actors from the field of sustainable finance (e.g. Dupré et al. 2013; UNEP Inquiry 2015; UNEP Inquiry 2016). Furthermore, I included organisations that were present at events on sustainable finance like the launch of the European Commission's High-level Expert Group on Sustainable Finance's (HLEG) interim report in July 2017, the UNFCCC Conference of Parties 23 in November 2017 and the Finance Day at the One Planet Summit in December 2017. The collection of actors was carried out on a rolling basis from May 2017 until the end of December 2017 and resulted in the sampling of a total of 242 organisations.

In the second stage, I assessed the knowledge production of these organisations. I rely on texts that are published under the name of one or more of the sampled organisations and are

\footnotetext{
${ }^{3}$ I gathered and analysed a total of 360 newspaper articles from Financial Times, Responsible Investor, Bloomberg, the Guardian, the Economist, Euractiv, Frankfurter Allgemeine Zeitung and die Zeit that were published between January 2017 and February 2020 on a rolling basis. A bibliographical listing is on file with the author.
} 
freely available. Rather than including all publications from the 242 organisations, I collected only those texts that match previously specified keywords. Keyword-based boundary specification is often applied to study knowledge production (Shwed and Bearman 2010).

The keywords that I use to determine whether a text is about sustainable finance are "sustainable finance", "green finance", "climate finance", "sustainability" and "climate change". In addition, I initially added the search term "Capital Markets Union”, which is linked to the EU's HLEG that started in late 2016 as well as to the EU's subsequent actions on sustainable finance Finally, I also included keywords on "alternative" or "ecologically reflexive" economic and financial systems to account for the different terminology that is used by some civil society and activist organisations that concern themselves with sustainable finance.

I collected 666 documents from 145 of the 242 organisations for the period between 1998 and 2018. The networks I construct are co-publication networks that link texts with joint authors. In contrast to citation links, which depict primarily a flow of information, copublication links also indicate a social dimension. This is because people producing a joint publication can be expected to engage in social interaction, which, in turn, can be interpreted as a marker for epistemic agreement.

\section{Text Analysis and Interviews}

While the application of the algorithm results in the identification of actor clusters, complimentary methods and data sources are needed to establish the content and meaning of the frames that are represented in these clusters. To identify the frames, I use qualitative content analysis of the texts that form the raw data for the co-publication networks. 
Qualitative content analysis allows for the inductive and recursive development of categories (Mayring 2000: 3) and thus integrates well with the detection of frames (cf. Entman 1993: 52). Instead of analysing all the texts that were sampled for the network analysis, I selected relevant publications with the help of network measures such as betweenness centrality. I also looked at texts that other data sources such as interviewees and news coverage identified as relevant.

Lastly, I conducted 25 elite interviews with sustainable finance experts between November 2017 and March 2019. The interviewees resulted from targeting individuals with high betweenness centrality scores in the co-publication networks. I equally sought to target interviewees that had contributed to several publications of a cluster. Accounts from these individuals can be interpreted as being broadly representative of the frame that is present in such clusters. The interviews were carried out in person in Berlin, Brussels and Geneva as well as over the phone. The length of the interviews varied between 20 minutes and 1.5 hours.

\section{The Evolution of the Framing in the Network of Sustainable Finance}

\section{Raw Data, Periodisation and Overview of the Frames}

The bar plot in figure 1 displays the publications and their contributors, i.e. the raw data that underlies the co-publication networks (figures 2 to 4). The level of knowledge production, which is measured by those statistics, rose steadily from 1998 until 2013. In 2014, a major expansion of publications and experts occurred with both categories increasing almost twofold. In 2015, another increase by the factor two can be observed. Since then, activity has plateaued.

To account for the fact that the contestation of sustainable finance and the different communities trying to impose their framing on the topic proceeds in historical time, I segment the analysis of the network into three periods. Existing historical analyses have also applied 
periodisations to the evolution of sustainable finance. These treatments separate time periods by themes like civil rights or ESG (cf. Dumas and Louche 2016: 439) or by the maturity and size of the issue (Crifo et al. 2019). When looking at sustainable finance by means of network analysis, a segmentation of the raw data provides the added benefit of dealing with the problem that links which represent dated social interactions are generally assumed to be less meaningful (cf. Young et al. 2017: 346).

In line with the inductive approach of the article, the chosen periodisation reflects periods that the literature has identified as meaningful for sustainable finance as well as changes in the raw data. The depicted periods thus illustrate general developments that could also be seen if a more granular (e.g. yearly) construction of the networks was undertaken. It falls, however, short of testing the impact of any exogenous factor.

In figure 1, the periods are indicated by the black-dotted lines. The first period starts in 1998. This is one year after 'Sustainable Investment' made its first appearance on the European political landscape with the publication of a study by the European Commission (Delphi and Ecologic 1997) and one year before the term 'Responsible Investment' appeared for the first time in the continental mainstream news (Gond and Boxenbaum 2013: 711). The endpoint of this first period is the year 2008, which saw the unfolding of the Global Financial Crisis. 2009 to 2014 are the start and endpoint of the second period. 2009, notably marks a new epoch in climate politics, which began with the widely accepted failure of interstate bargaining at the Copenhagen CoP in 2009 (Bernstein et al. 2010: 162ff). The last period begins in 2015 and ends in 2018 when data collection stops following the publication of the EU's Action Plan on Financing Sustainable Growth (EC 2018). The start of the third period in 2015 is characterised by the Paris Agreement, the publication of the UN Sustainable Development Goals, as well as a major shift in the data, i.e. the two-fold increase of contributors and texts. 


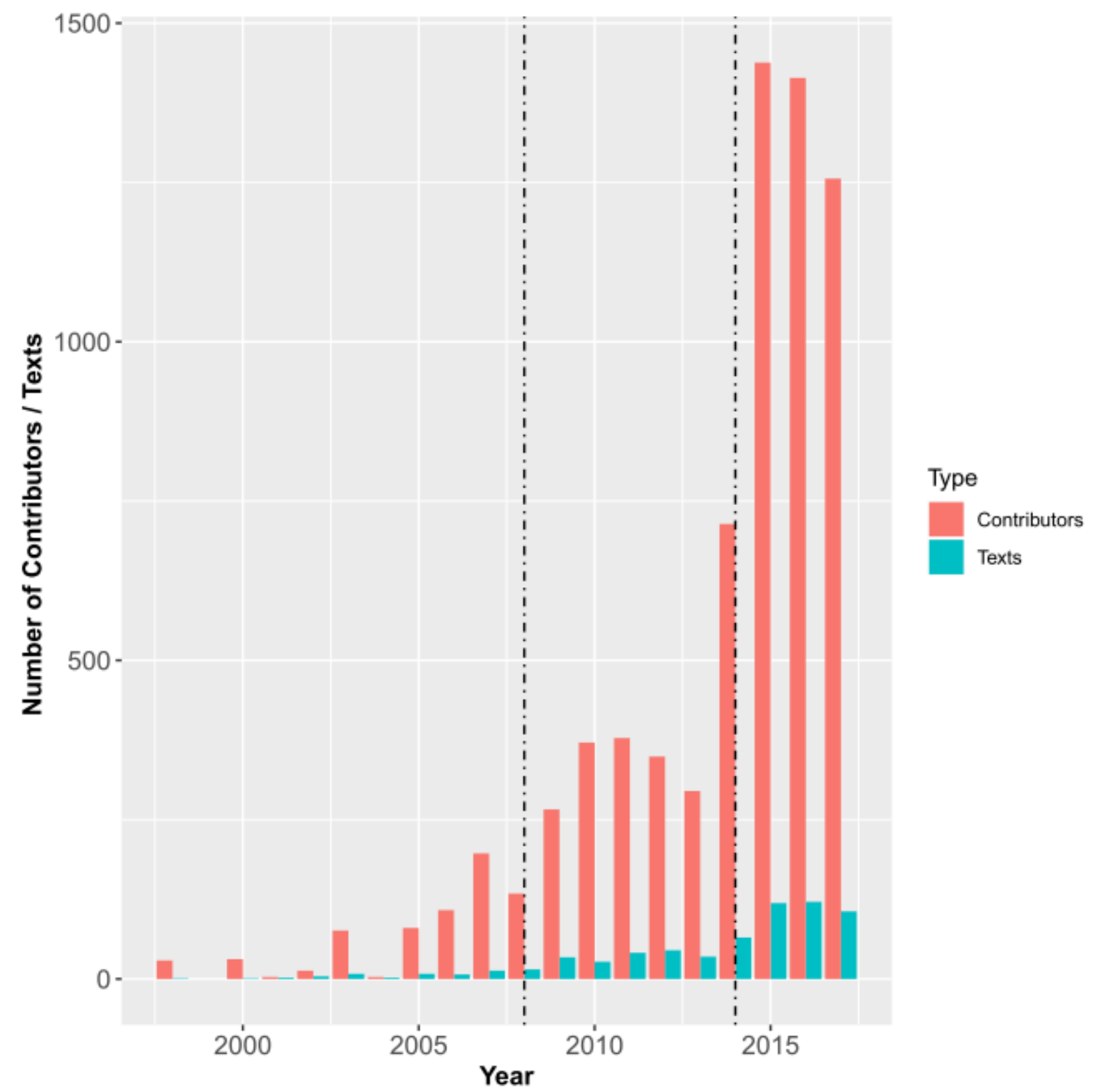

Figure 1. Evolution of contributors and texts that are subject to the network analysis per year. In total 666 unique texts and 5629 unique individuals were identified (i.e. no double counting). While some observations from 2018 are included in the discussion below, they are not represented in figure 4.1, because I stopped comprehensive sampling in December 2017.

Before starting the description, table 1 already summarises the five frames that have been found in the expert network of sustainable finance in order of their chronological appearance. First, there is the SRI frame that reflects the ethical motivations of early sustainable investors. The second frame is associated with a view that understands sustainable finance as the integration of sustainability issues into the traditional risk and return calculus of investment 
decision making. Third, there is the critical frame that has been adopted mostly by civil society actors, which emphasise that the financial sector is part of the problem when it comes to sustainability. Fourth, the climate finance frame emphasises the financial sector's role in making the investments that are necessary for a low carbon transition. Finally, and most recently, hub-creating actors advanced an integrated frame that seeks to promote all the different facets of sustainable finance.

\begin{tabular}{|c|c|c|}
\hline Frame & Main Emphasis & Selected Actors \\
\hline $\begin{array}{l}\text { Socially Responsible } \\
\text { Investment (SRI) }\end{array}$ & $\begin{array}{l}\text { Align investments to ethical } \\
\text { views of investors }\end{array}$ & $\begin{array}{l}\text { Eurosif and its member } \\
\text { organizations }\end{array}$ \\
\hline Risks and Opportunities & $\begin{array}{l}\text { Integrate ESG issues and } \\
\text { especially climate-related } \\
\text { risks into investment } \\
\text { decisions }\end{array}$ & $\begin{array}{l}2^{\circ} \text { investing, UNEP FI, Carbon } \\
\text { Tracker, FSB TCFD, NGFS }\end{array}$ \\
\hline Critical & $\begin{array}{l}\text { Hold the actors that } \\
\text { reproduce a dysfunctional } \\
\text { and environmentally and } \\
\text { social damaging financial } \\
\text { system to account }\end{array}$ & $\begin{array}{l}\text { Nef, urgewald, RAN, Bank } \\
\text { Track, FoE }\end{array}$ \\
\hline Climate Finance & $\begin{array}{l}\text { Leverage capital from the } \\
\text { financial system to finance } \\
\text { the transition towards a low } \\
\text { carbon economy }\end{array}$ & CPI, NCE, IIGCC \\
\hline Integrated Frame & $\begin{array}{l}\text { Promote all parts of } \\
\text { sustainable finance }\end{array}$ & $\begin{array}{l}\text { UNEP Inquiry, HLEG, G20 } \\
\text { study group }\end{array}$ \\
\hline
\end{tabular}

Table 1 Frames in Sustainable Finance Between 1998 and 2018 


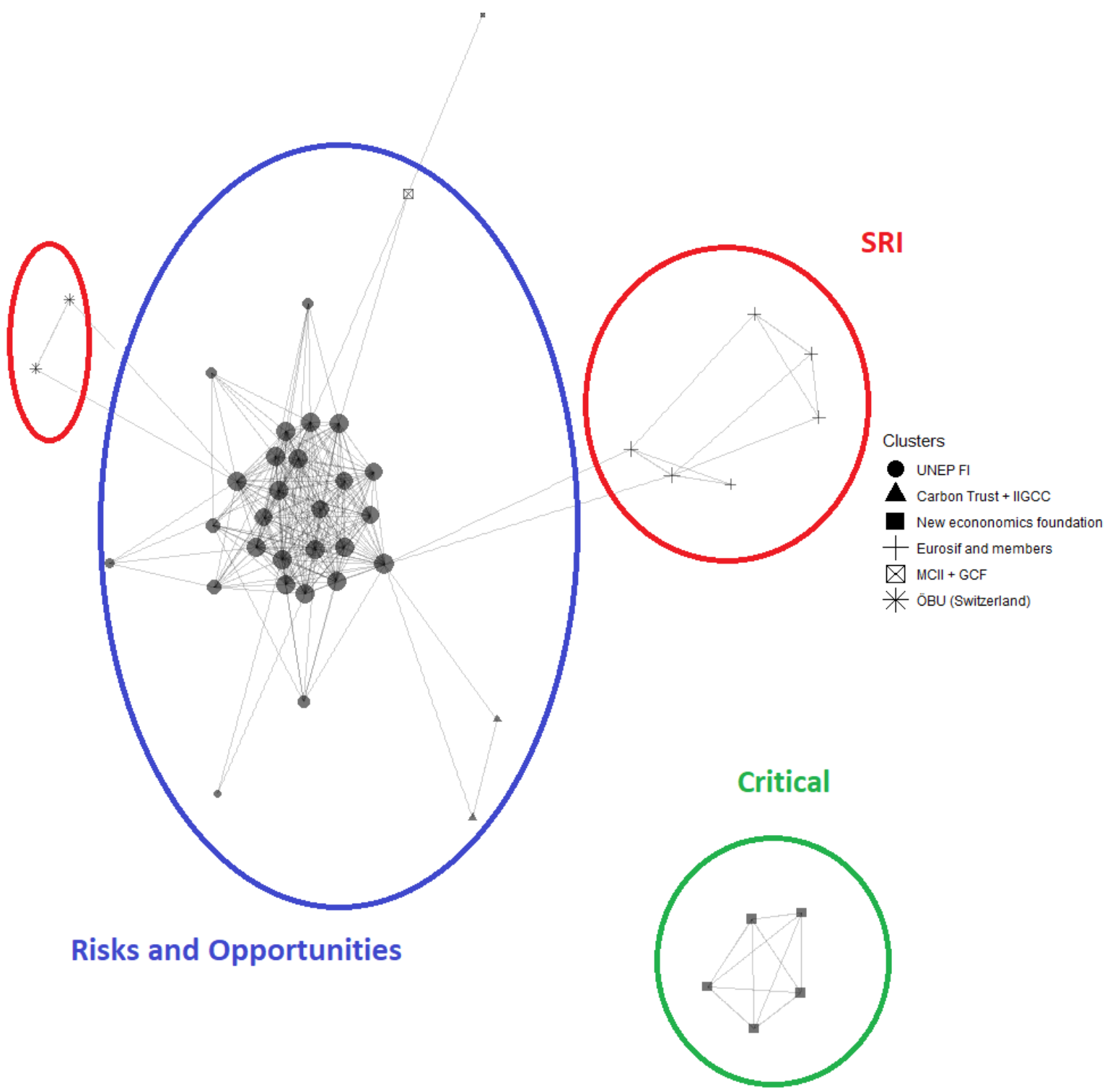

Figure 2 Co-publication Network 1998-2008. Nodes are scaled by degree. Symbols correspond to cluster membership as detected by the Girvan-Newman Algorithm. Abbreviations in the legend: Global Climate Forum $(G C F)$, Institutional Investor Group on Climate Change (IIGCC), Munich Climate Insurance Initiative (MCII), Schweizierische Vereinigung für Ökologisch Bewusste Unternehmensführung (ÖBU), United Nations Environment Programme Finance Initiative (UNEP FI).

Figure 2 represents the links between texts with joint publishers for the period between 1998 and 2008. The algorithm identified six clusters for the co-publication network in the period, which are displayed through different node symbols. The names of the organisations that 
associated to the clusters are listed in the legend on the right side of figure 2. Subsequently, I used qualitative text analysis and interview data to superimpose three frames on the clusters. These frames are Socially Responsible Investment (SRI), Risks and Opportunities and the Critical Frame.

I start by discussing SRI, which in the figure is represented by publications from eurosif, the European umbrella trade association of SRI firms (plus-shaped nodes). ÖBU, the Swiss trade association of SRI funds constitutes a separate cluster that is geographically removed but can equally be attributed to this frame (star-shaped nodes).

SRI is often considered as a synonym for ethical investment (Schoenmaker 2017; Robins and McDaniels 2016). While the first ethical funds have been dated back to 1928 in the US and to 1948 in the UK (Gond and Boxenbaum 2013: 710; Sparkes 2002: 27, 48), SRI started to grow in the 1970s and 1980s in the Anglo-American context. SRI has its roots with ethical and often religious investors, most of whom have an evangelical Christian background (Sparkes 2002: 48ff). These actors seek to align their activities on the capital markets with their beliefs (Sparkes 2002: 27ff). SRI pioneers like the Interfaith Centre on Corporate Responsibility try to exclude the financing of sectors and products they consider harmful or unethical. Examples are tobacco and armaments but also contraception (Co-Founder, Sustainability Consultancy, October 3rd, 2018). Another variation of SRI are positive screens, which include the strategic selection of 'good' sectors (e.g. renewable energy) and so called best-in-class approaches. In the latter case only assets of the best companies (e.g. in terms of low pollution or respect for labour rights) of each sector can be chosen (Sparkes 2002: 29).

The second frame, which is depicted in the centre of figure 2 , is the risks and opportunities frame. This frame started to gain traction in the 1990s as SRI funds grew in volume and the topic of ethical or responsible investment appeared increasingly on the radar of larger financial institutions. In the figure, the risks and opportunities frame is mostly 
represented by publications that were authored or coordinated by the United Nations Environment Programme's Finance Initiative (UNEP FI). UNEP has been active on linking finance with environmental concerns since the creation of its Banking initiative in the run-up to the Rio Earth Summit in 1992. In 2003 the Banking initiative was merged with the Insurance initiative to become UNEP FI. Rather than working on expanding the niche of SRI, UNEP focused on convincing existing 'market leaders', in insurance, banking and asset management of the merits of including sustainable development considerations (IO Staffer, July 20th, 2018).

To engage these actors, UNEP FI publications addressed environmental issues in a language and conceptual framework that is familiar to these institutions, i.e. risks and opportunities. Reports from the early 2000s emphasised the opportunities of the Clean Development Mechanism and other cap and trade mechanisms for the financial sector (e.g. Basson et al. 2005; Dlugolecki et al. 2002). A second emphasis of the UNEP FI publications are the risks linked to ESG factors. Examples are increased losses for insurers as natural catastrophes linked to climate change occur more frequently (Dlugolecki et al. 2002: 2-3) and risks related to biodiversity and ecosystem services (Clements-Hunt et al. 2008). The efforts of constructing ESG issues as business risks also highlighted the importance of standardising company disclosures through initiatives like Global Reporting Initiative (GRI) and or the CDP (formerly Carbon Disclosure Project) (Pattberg 2012)

The third frame is the critical frame, which, notably, has no links to the centre of the graph in figure 2 . This frame was advanced by civil society and research organisations like the British New Economics Foundation (nef). These actors approached the financial system out of an understanding that highlights its role in the creation and re-production of global inequalities (e.g. Simms 2001). In terms of environmental sustainability and climate change more narrowly, the nef also questioned of the imperatives of economic growth and capital accumulation (Simms 2001: 18). This systemic criticism received new impetus through the Global Financial Crisis. 
Accordingly, the increasing deregulation of the financial system since the 1970s had not only led to the crash and exacerbated inequalities but was also linked with environmental issues by amongst others fuelling overconsumption through the extension of credit (Elliot et al 2008: 912).

In summary, I identify three frames in the first period. First, there is the SRI frame that is associated with traditional ethical investors. The second frame is the risks and opportunities frame, which is associated with UNEP FI and aims to persuade large financial institutions to embrace sustainable finance. Finally, the critical frame, which is advanced by CSOs, maintains that the financial system is detrimental to environmental and social sustainability and hence needs to undergo major reform. 
2009-2014: Emergence of the Climate Finance Frame and Narrowing Down of Risks and

\section{Opportunities to Climate Issues}
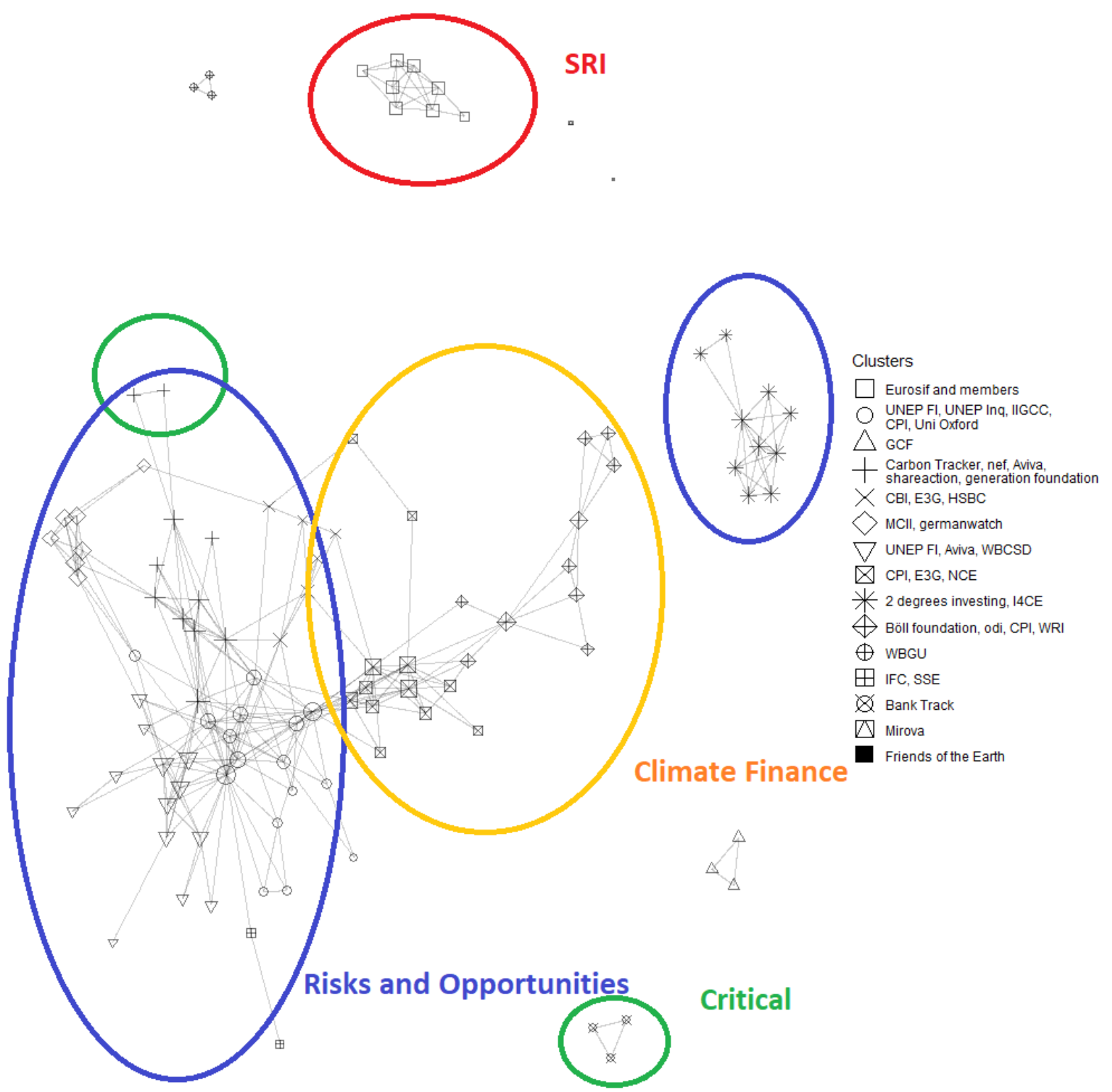

Figure 3. Co-publication Network 2009-2014. Symbols correspond to cluster membership as detected by the Girvan-Newman Algorithm Abbreviations in the legend: Climate Bonds Initiative (CBI), Climate Policy Initiative (CPI), Third Generation Environmentalism (E3G), Global Climate Forum (GCF), Institute for Climate Economics (I4CE), International Finance Corporation (IFC), Institutional Investor Group on Climate Change (IIGCC), Munich Climate Insurance Initiative (MCII), New Climate Economy (NCE), New Economics Foundation (nef), Overseas Development Institute (odi), Sustainable Stock Exchanges Initiative (SSE), World Business Council for Sustainable Development (WBCSD), World Resources Institute (WRI). 
Figure 3 describes the co-publication network between 2009 and 2014. Apart from the growing actor population (see also figure 1), one can observe a more marked community structure. This is a product of the increase in number of clusters from 6 to 15. Figure 3 also reveals that the SRI frame has become increasingly marginalised. Whereas SRI actors were still connected to the main part of the network in figure 2, they are now represented as an isolate component. The largest part of the graph is again occupied by the risks and opportunities frame (lower left of figure 3). Notably, the previously observed dominance of UNEP FI within this frame has weakened.

The advent of new actors that framed sustainable finance in terms of risks and opportunities also meant a variation in content and emphasis. Starting from around 2011, universities and CSOs began to engage with sustainable finance through the risks and opportunities frame. Against the background of the Global Financial Crisis, these actors suggested that environmental risks might be the subject of the next financial crisis. By outlining how environmental factors and climate change in particular relate to financial risk, they managed to attract the attention (albeit not yet the financial decisions) of financial institutions (IO Staffer, July 3rd, 2018).

This narrowing down is strongly associated with the concepts of 'unburnable carbon' and 'stranded assets'. These terms were coined by the UK-based Carbon Tracker Initiative (among the plus-shaped nodes in figure 3). Carbon Tracker used carbon budget calculations, i.e. the amount of GHG emissions still available to humanity under a below $2^{\circ}$ scenario, to quantitatively measure how overvalued carbon-intensive assets are. A below $2^{\circ}$ scenario means that only one fifth of the available fossil fuel reserves can be burned. It follows that financial assets (e.g. shares, bonds), whose price is related to the valuation of fossil fuel dependent physical assets (e.g. oil tankers, coal mines) that cannot be utilised in a below $2^{\circ}$ scenario are overvalued. Once policy makers take actions to guarantee that the excess carbon reserves are 
not burned (thus unburnable carbon), the assets based on them will undergo a significant downward correction, i.e. become stranded (Leaton 2013).

Interviewees repeatedly highlighted the significance of Carbon Tracker and the stranded asset concept (IO Staffer, July 3rd, 2018, Think Tank Research Director, September 29th, 2018, University Researcher, October 31st, 2018). Other organisations that contributed to the reformulation of the risks and opportunities frame in this period are the University of Oxford's Smith School and the 2 Degrees Investing Initiative $\left(2^{\circ}\right.$ investing, star-shaped nodes in figure 3), the latter being an initially France-based think tank that from 2012 worked on concepts, metrics, scenarios and indicators of climate risk (cf. Dupré and Chenet 2012).

In addition, climate-related physical risks received increasing attention. This category highlights financial losses that accrue to investors, whose portfolios are based on assets that would be destroyed by physical impairments (e.g. flooded real estate) or business model disruptions (e.g. disruption of a supply chain or increase in prices of an agricultural commodity due to droughts) that are due to climate change (Caldecott and McDaniels 2014).

The critical frame also underwent some changes. Some actors started to critically assess the claims made by market leaders that associated themselves with UNEP FI during the first period. Bank Track, urgewald, the Centre for Research on Multinational Corporations, the Rainforest Action Network, Friends of the Earth and Oil Change International are some of the CSOs that scrutinised the sustainability credentials of large financial institutions and shamed those that failed to live up to their promises. The framing of these actors also emphasises divestment from environmentally harmful activities such as coal mining (e.g. Van Gelder et al 2010).

Finally, a new frame emerged, which in figure 3 is situated towards the right of the main component. The proponents of this frame emphasised the necessity for additional climate finance. One of the main diagnoses of this 'climate finance frame' is that the transition towards 
low-carbon economies requires investments at a scale that cannot be financed by public budgets. Illustrating this line of argumentation, article 8 of the Copenhagen Accord emphasises that private finance will count towards the financial flows from developed to developing countries (UNFCCC 2009). One interviewee pointed out that the accord's commitment to the yearly flow of US \$ 100 billion in climate-related development funds by 2020 played an instrumental role in the development of the climate finance community as private and CSO actors sought to track and leverage this funding (Staffer, Climate Finance CSO, February 17th, 2019). The advocates of the climate finance frame also pointed to the role of green bonds and 'blended finance.' The latter connects public with private funding through risk-sharing mechanisms or other subsidies (e.g. Buchner et al. 2012).

The concept of a green growth model displays a similar framing. Accordingly, the New Climate Economy (NCE), a multi-stakeholder collaboration that includes CSOs like the Climate Policy Initiative (CPI) as well as IOs such as the IMF, the World Bank and the OECD argued for the facilitation of new financial instruments in the realm of development financing (NCE 2014: especially 25ff, 33ff).

In summary, in this second period the SRI frame was further marginalised. The risks and opportunities frame expanded but was also transformed to account almost exclusively for risks related to climate change. CSOs and think tanks like Carbon Tracker and $2^{\circ}$ investing played a role in popularising this approach. Concurrently, a new climate finance frame came into focus seeking to mobilise the financial sector behind climate change related projects. Lastly, the critical frame continues to be isolated but increasingly brings together a wellconnected CSO community that monitors the promises of financial institutions. 


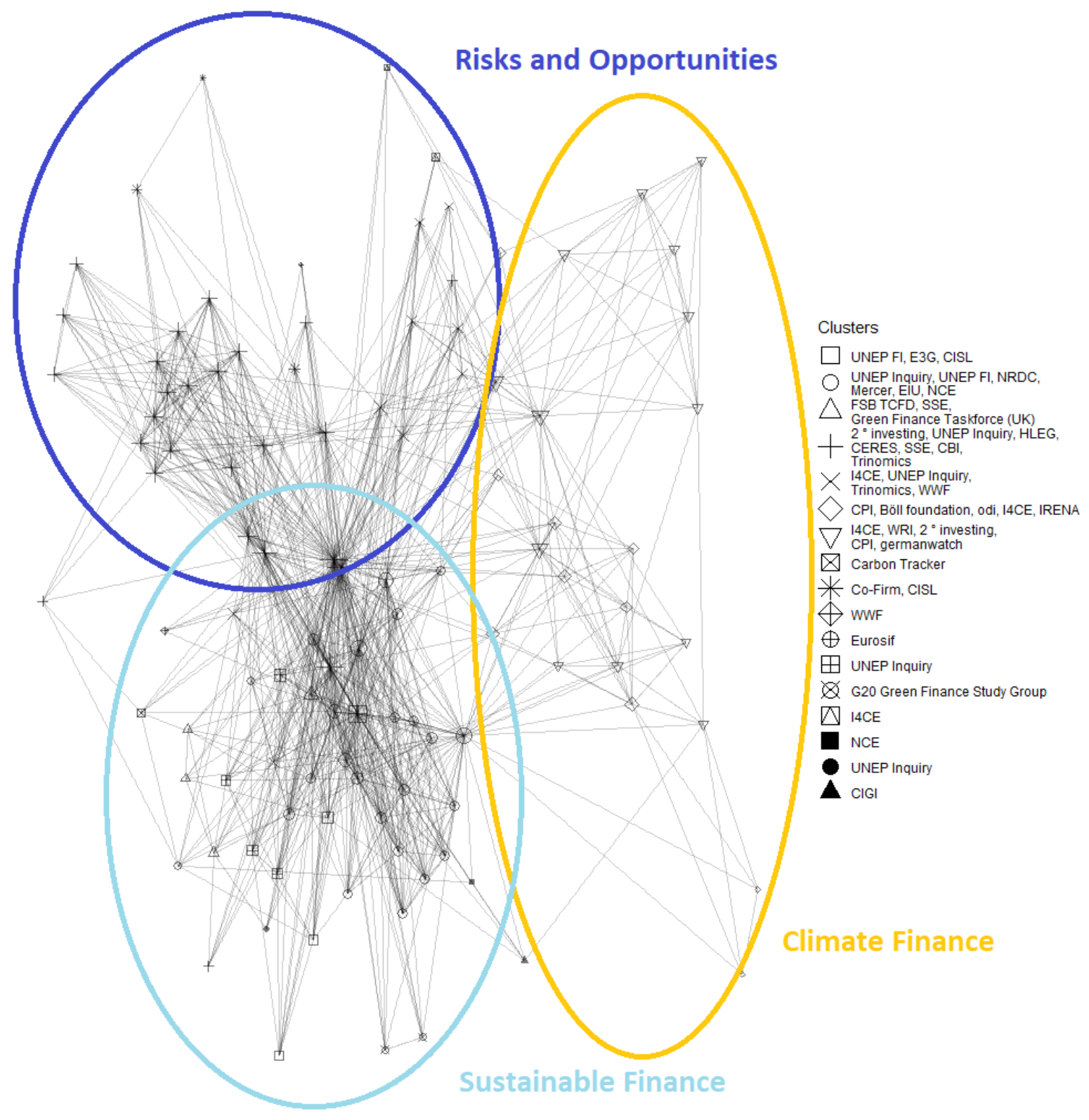

Figure 4. Co-publication Network 2015-2018 Symbols correspond to cluster membership as detected by the Girvan-Newman Algorithm Abbreviations in the legend: Climate Bonds Initiative (CBI), Cambridge Institute for Sustainability Leadership (CISL), Centre for International Governance Innovation (CIGI), Climate Policy Initiative (CPI), Third Generation Environmentalism (E3G), Economist Intelligence Unit (EIU), EU High-level Expert Group on Sustainable Finance (HLEG), Financial Stability Board Taskforce on Climate-related Disclosures (FSB TCFD), Institute for Climate Economics (I4CE), International Renewable Energy Agency (IRENA), New Climate Economy (NCE), Natural Resources Defense Council (NRDC), Overseas Development Institute (odi), Sustainable Stock Exchanges Initiative (SSE), World Resources Institute (WRI), World Wide Fund for Nature $(W W F)$ 
Figure 4, which represents the period between 2015 and 2018, shows a further increase in the actor population. In total, there are 17 clusters, which I have attributed to 3 frames. As in the previous period, the risks and opportunities frame and the climate finance frame are well represented. A new development in this period is the increasing presence of hub-creating actors that try to establish bridges between the formerly sparsely connected frames of climate finance and risks and opportunities. These actors thus advance integrated frame that seeks to account for all parts of sustainable finance.

While the integrated frame provided a point of connection between the different communities, the inclusiveness of the term sustainable finance, which now was increasingly used to refer to the whole system, should not be overestimated. An interviewee noted that while being inclusive, the concept is also a misnomer. This is because in practice sustainable means mostly environment, which means climate, which, in turn, means carbon emissions (IO Staffer, July $3 r d, 2018$ ). This assessment is seconded by another interviewee, who remarked that " $80 \%$ of sustainable finance is climate.” (Think Tank Research Director, September 29th, 2018).

The risks and opportunities frame, which still occupied the greatest share of what now was called sustainable finance, continued its movement away from ambiguity towards more sophistication and specificity. An important step in this process was to standardise the categorisation of climate-related risks. In 2015, the Bank of England's Prudential Regulation Authority (PRA) published a report on climate-related risks for insurance firms (PRA 2015). According to the assessment of interviewees, the PRA was instrumental in defining and popularising the notion of climate-related risks (IO Staffer, July 3rd, 2018; Staffer, Responsible Investment CSO, December 17th, 2018). A similar development happened in France with the adoption of the 2015 Energy Transition Law. The internationalisation and institutionalisation of these efforts by central banks and supervisors took place at the One Planet Summit in December 2017 with the establishment of the NGFS. The NGFS is a collaboration of financial 
authorities that coordinates the development of methodologies, supervisory practices and regulatory interventions on climate-related risks (cf. NGFS 2019).

In parallel to the work of financial supervisors, one major step in the assessment of climate-related risks was the development of forward-looking metrics such as scenario analyses. These tools increasingly complemented disclosure-based and backward-looking assessments such as GHG foot-printing. One influential actor in developing such methodologies is $2^{\circ}$ investing (plus-shaped nodes in figure 4; e.g. Thomä et al. 2015, cf. Economist, Environmental Agency, January 24th, 2019). The importance for forward-looking data is also stressed by the Financial Stability Board's Taskforce on Climate-related Financial Disclosures (FSB TCFD). The taskforce, which was established in 2015, is led by actors from the private sector and its main objective is to standardise corporates' and financial institutions' forward-looking reporting on material climate-related risks (FSB TCFD 2017). The TCFD forcefully emphasised the necessity of complete, accurate and standardised data so that financial institutions can do their job of pricing assets correctly.

While the risks and opportunities frame continued to be the dominant interpretation of the fuzzy term sustainable finance, the climate finance frame increasingly emerged as a complementary approach. The NCE continued its efforts with studies and policy suggestions on how to operationalise the new green growth regime (e.g. NCE 2016). Meanwhile, the OECD conducted its own economic demonstration of the positive GDP effects of climate mitigation (OECD 2017). In this context, one interviewee noted that from $2015 / 16$ onwards "sustainable finance [became] the new green growth" as many researchers that had published on green growth around 2011/12 were now working on sustainable finance (University Researcher, October 31st, 2018).

The discussion within the climate finance frame occurred against the background of a period, in which safe assets paid close to zero interest. On the other hand, the annual funding 
gaps for energy, climate or SDG investments were estimated in the range of trillions of US \$. These two observations were almost routinely brought together in the climate finance frame. The advocates of this frame emphasise the necessity of connecting the trillions of institutional investments that are in search of for safe, long-term return to the funding needs of the new global green growth regime (e.g. Moslener et al. 2015: 4ff; NCE 2016: 16; UNEP Inquiry 2015: XIII).

Finally, while the advocates of the SRI and the critical frame have remained active, they do not account for any major clusters in figure 4 . As to the SRI frame, figure 4 shows that eurosif still maintains connections to the centre. The marginalisation of the SR community can, however, be evidenced by the statement of one interviewee from the SRI community, who remarked that SRI actors found it increasingly difficult to be heard in the debates on sustainable finance (Board Member, SRI association, September 21st, 2018).

Proponents of the critical frame are not directly represented in the figure. Nonetheless, there are some indications that relatively central actors incorporated parts of this frame. UNEP Inquiry, one of the hub-creating actors, has, for example, come forward with publications that question the functionality and the performance of the financial system when benchmarked against environmental categories (UNEP Inquiry 2015; 2016). In addition, the emphasis on systemic connections between finance and sustainability, which was an early concern of the critical frame, has been arguably incorporated into the discussions among the regulators and central banks. The discussions in the "Green Swan report" that was published by the Bank for International Settlements are a case in point (Bolton et al. 2020). 


\section{Discussion}

When looking at the history of sustainable finance through the lenses of contested concepts and frames, one can observe dynamics that lie in between the chaotic ambiguity that the treatment of the issue as an empty signifier suggests and the linear evolution that features in some historical analyses. Sustainable finance does, indeed, mean different things to different actors at different times. Yet those meanings are neither completely arbitrary, nor do they follow a staged trajectory where one neatly evolves into the other. Instead, variations in the dominant meaning of the concepts occurred as actor groups that employ a shared framing become central or peripherical in the expert network. The increasing delinking of the SRI frame from the core of the network and its progressive replacement by the risks and opportunities frame is a case in point.

A further variation in the meaning of sustainable finance can occur within actor groups that employ a shared framing, as the overall focus remains constant but emphasis and operationalisation might change. The changes of the risks and opportunities frame show, for instance, that it moved from a broad understanding of ESG issues to an almost exclusive focus on sophisticated assessments of climate-related risks. This has made sustainable finance as understood in terms of risks and opportunities less ambiguous but by the same token also less inclusive.

A final observation concerns the interaction between frames, or the extent to which there is contestation or collaboration between them. As seen above, the risks and opportunities frame contested and overwhelmingly displaced the SRI frame. Meanwhile, the hub-creating actors tried to make the network more cohesive by establishing links that integrate the risks and opportunities frame and the climate finance frame. Finally, despite remaining at the margins of the expert network, actors from the critical frame have managed to establish some links and, thereby, to influence and collaborate with some of the more central actors. 
The inductive approach taken in this paper means that hypotheses for explaining which factors lead to contestations and which lead to collaboration necessarily remain speculative. With this caveat in mind, one could look to ideational, economic and sociological differences and complementarities. An ideational explanation would emphasise the different world views that are connected to the frames. For instance, the preoccupation with ethics and non-financial impact of the SRI frame might not be reconcilable with the risks and return calculus of the risks and opportunities frame. By contrast, the emphasis on novel financial instruments that is displayed by the climate finance frame could be integrated with the ideas underlying the risks and opportunities frame.

Interestingly, there might also be a complementarity between the risks and opportunities and the critical frame if one shifts the level of risk analysis to the entire financial system. Thus, ideational differences should be treated as dynamic rather than as absolute. An economic explanation could zoom in on rivalries and complementarities in terms of demand and supply. A possible complementarity could be related to green bonds, which are advocated for by the climate finance frame and demanded by investors that are concerned with risks and opportunities. Meanwhile, competitive dynamics could exist between the SRI and the risks and opportunities frame as institutional investors compete with traditional SR investors for retail customers. Finally, a sociological explanation could draw on the work on expert networks and the sociology of professions by examining to what extent shared frames are related to similar professional and training trajectories. 


\section{Conclusion}

This article has argued that the ambiguity surrounding sustainable finance can be understood as being the product of a contested concept. Actors' interpretations of this concept, in turn, can be inductively observed by looking at the frames that are present in the expert network that produces knowledge about sustainable finance. The identification of different frames can add to our understanding of the history of sustainable finance by providing a contextualised rather than a linear account of the topic's evolution.

The differences and complementarities between frames can help to better understand some of the ongoing debates in sustainable finance. Moreover, observations on the peripheral positions of some frames such as the SRI and the critical frame ones can be useful to note conspicuous absences in the current debates on sustainable finance. For example, the uneasy relationship between the risks and opportunities frame, the SRI frame and the critical frame can serve as background when discussing issues such as the relation of environmental impacts with financial materiality or the issue of fiduciary duties. While the identification of frames is a first step to understand what sustainable finance is and was, future research is needed to clarify the implications of this. As the frames remain only on the discursive level, it would be worth to investigate how they translate to the practices of financial institutions or the content of regulations. 


\section{Bibliography}

Ban, C. (2015). Austerity versus Stimulus? Understanding Fiscal Policy Change at the International Monetary Fund Since the Great Recession. Governance, 28(2), 167-183.

Basson, T., Boal, J., Challoner, A., Coleman, T., Häßler, R. D., Kohler D. P., Sahi, H. M., Sandhövel, A., Schärer, S. \& Weyman, M. (2005). The Future of Climate Policy, The Financial Sector Perspective. UNEP FI.

Benford, R. D., \& Snow, D. A. (2000). Framing processes and social movements: An overview and assessment. Annual Review of Sociology; 26, 611-639.

Bernstein, S., Betsill, M., Hoffmann, M., \& Paterson, M. (2010). A Tale of Two Copenhagens: Carbon Markets and Climate Governance. Millennium - Journal of International Studies, 39(1), $161-173$.

Bolton, P., Despres, M., Da Silva, L. A. P., Samama, F., \& Svartzman, R. (2020). The Green Swan: Central Banking and Financial Stability in the Age of Climate Change. Bank for International Settlements. January 2020.

Borgatti, S. P., Everett, M. G., \& Johnson, J. C. (2013). Analyzing social networks. London: Sage Publications.

Buchner, B., Heller, T. C., \& Wilkinson, J. (2012). Effective Green Financing: What have we learned so far. Venice: Climate Policy Initiative.

Burt, R. S. (1992) Structural Holes. Cambridge, MA: Harvard University Press

Caldecott, B., \& McDaniels, J. (2014). Financial Dynamics of the Environment: Risks, Impacts, and Barriers to Resilience. Working Paper for the UNEP Inquiry.

Clapp J. \& Thistlethwaite J. (2012). Private voluntary programs in environmental governance: Climate change and the financial sector. In Ronit, K. (Ed.). Business and climate policy: the potentials and pitfalls of private voluntary programs. (pp. 43-76).

Clements-Hunt, P., Steinhagen, S., Abadie, A., Eckstein, M., Rose, M. \& Grigg, A. (2008). Biodiversity and Ecosystem Services: Bloom or Bust? UNEP FI.

Connelly, S. (2007). Mapping sustainable development as a contested concept. Local environment, 12(3), 259-278.

Crifo, P., Durand, R., \& Gond, J.-P. (2019). Encouraging Investors to Enable Corporate Sustainability Transitions: The Case of Responsible Investment in France. Organization \& Environment, 32(2), 125-144.

Dlugolecki, A., Gold, I., Szauer, M. T., Sandhövel, A., Kohler, D. P., Loster, T., Lynds, F., Le Duc, C., Streiff, T., Clements-Hunt, P. (2002). CEO Briefing. A Document of the UNEP FI Climate Change Working Group.

Dumas, C., \& Louche, C. (2016). Collective Beliefs on Responsible Investment. Business \& Society, 55(3), 427-457.

Dupré. S, \& Chenet H. (2012). Connecting the Dots between Climate Goals, Portfolio Allocation and Financial Regulation. $2^{\circ}$ investing initiative.

Dupré, S., Chenet H., Thomä, J. \& Guylaine, D. (2013): From Financed Emissions to Long Term Strategies: State of the Art Review of GHG Emissions Accounting for the Financial Sector. $2^{\circ}$ investing initiative. 
Eccles, N. (2013). Sustainable investment, Dickens, Malthus and Marx. Journal of Sustainable Finance \& Investment, 3(4), 287-302.

Elliot, L., Hines, C., Juniper, T., Lucas, C., Murphy, R., Pettifor, A., Secrett, C. \& Simms, A. (2008). A Green New Deal: Joined-up policies to solve the triple crunch of the credit crisis, climate change and high oil prices.

Entman, R. M. (1993). Framing: Toward Clarification of a Fractured Paradigm. Journal of Communication, 43(4), 51-58.

European Commission (2018). COM (2018) 97 final: Action Plan: Financing Sustainable Growth.

European Commission (2020). COM (2020) 456 final. Europe's moment: Repair and Prepare for the Next Generation.

Forstater, M., Zhang, N.N. (2016). Background Note: Definitions and Concepts. UNEP Inquiry Working Paper 16/13.

FSB TCFD (2017). Final Report: Recommendations of the Task Force on Climate Related Financial Disclosures.

G20 Green Finance Study Group. (2017). G20 green finance synthesis report 2017. G20 Green Finance Study Group: Sanya, China.

Gallie, W. B. (1955). Essentially contested concepts. In Proceedings of the Aristotelian society (Vol. 56, pp. 167-198).

Girvan, M., \& Newman, M. E. J. (2002). Community structure in social and biological networks. Proceedings of the National Academy of Sciences, 99(12), 7821-7826.

Gond, J., \& Boxenbaum, E. (2013). The Glocalization of Responsible Investment: Contextualization Work in France and Québec. Journal of Business Ethics, 115(4), 707-721.

Haigh, M. (2012). Publishing and defining sustainable finance and investment. Journal of Sustainable Finance \& Investment, 2(2), 88-94.

Henriksen, L. F., \& Seabrooke, L. (2016). Transnational organizing: Issue professionals in environmental sustainability networks. Organization, 23(5), 722-741.

High-level expert group on sustainable finance, HLEG. (2017). Financing a sustainable European economy: Interim report of the High-level expert group on sustainable finance.

Hjerpe, M., \& Buhr, K. (2014). Frames of Climate Change in Side Events from Kyoto to Durban. Global Environmental Politics, 14(2), 102-121.

Hoffmann, M. J. (2011). Climate governance at the crossroads: experimenting with a global response after Kyoto. Oxford; New York: Oxford University Press.

IMF (2019). Global Financial Stability Report: Lower for Longer. October 2019.

IMF (2020). Global Financial Stability Report: Markets in the Time of COVID-19. April 2020.

Jacobs, M. (1999b) Sustainable development as a contested concept, in: A. Dobson (Ed.) Fairness and Futurity (Oxford, Oxford University Press).

Jones, L (2020). \$1Trillion Mark Reached in Global Cumulative Green Issuance: Climate Bonds Data Intelligence Reports: Latest Figures. Climate Bonds Initiative. December $15^{\text {th }}$, 
2020. https://www.climatebonds.net/2020/12/1trillion-mark-reached-global-cumulativegreen-issuance-climate-bonds-data-intelligence. (Accessed January $9^{\text {th }}, 2021$ ).

Journal for Sustainable Finance and Investment (2021). Aims and Scope. https://www.tandfonline.com/action/journalInformation?show=aimsScope \&journalCode=tsfi 20 . (Accessed January $15^{\text {th }}, 2021$ ).

Knoke, D. (1993). Networks of Elite Structure and Decision Making. Sociological Methods \& Research, 22(1), 23-45.

Leaton, J. (2013). Unburnable Carbon 2013: Wasted Capital and Stranded Assets. Carbon Tracker \& Grantham Research Institute.

Maulemans, M. (2017). Beyond Direct Deals : How Fund Investing Adds to Your Impact Portfolio. Pymwymic Field Building Center.

Micilotta, F., Gavrilut, I. \& Rasbach, S. (2016). European SRI study 2016. Eurosif.

MacLeod, M., \& Park, J. (2011). Financial Activism and Global Climate Change: The Rise of Investor-Driven Governance Networks. Global Environmental Politics, 11(2), 54-74.

Mayring, P. (2000). Qualitative Content Analysis Forum Qualitative Sozialforschung.

Moslener, U., Thomä, J., Sonerud, B., Grüning, C., Cochran, I., Dupré, S., Bolscher, H., Eichler, L. \& Perroy, L. (2015). Shifting private finance towards climate-friendly investments: policy options for mobilising institutional investors' capital for climate-friendly investment.

Neville, K. J., Cook, J., Baka, J., Bakker, K., \& Weinthal, E. S. (2019). Can shareholder advocacy shape energy governance? The case of the US antifracking movement. Review of International Political Economy, 26(1), 104-133.

Newman, M. E. J. (2010). Networks: an introduction. Oxford ; New York: Oxford University Press.

Newell, P., \& Paterson, M. (2010). Climate capitalism: Global warming and the transformation of the global economy. Cambridge ; New York: Cambridge University Press.

NCE (2014). Better growth, better climate. The New Climate Economy Report. Washington, DC.

NCE (2016). The sustainable infrastructure imperative: financing for better growth and development. London, UK.

NGFS (2019). First Comprehensive Report: A call for action Climate change as a source of financial risk. April 2019.

OECD (2017). Investing in Climate, Investing in Growth, OECD Publishing, Paris.

Paterson, M. (2001). Risky Business: Insurance Companies in Global Warming Politics. Global Environmental Politics, 1(4), 18-42.

Paterson, M. (2010). Legitimation and Accumulation in Climate Change Governance. New Political Economy, 15(3), 345-368.

Paterson, M., \& Stripple, J. (2010). My Space: Governing individuals' carbon emissions. Environment and Planning D: Society and Space, 28(2), 341-362. 
Pattberg, P. (2012). How Climate Change Became a Business Risk: Analyzing Nonstate Agency in Global Climate Politics. Environment and Planning C: Government and Policy, 30(4), 613-626.

Prudential Regulation Authority, PRA (2015). The impact of climate change on the UK insurance sector.

Carolina Rezende de Carvalho Ferreira, M., Amorim Sobreiro, V., Kimura, H., \& Luiz de Moraes Barboza, F. (2016). A systematic review of literature about finance and sustainability. Journal of Sustainable Finance \& Investment, 6(2), 112-147.

Riding, S. (2020, June 13). Majority of ESG funds outperform wider market over 10 years. Financial Times.

Rinscheid, A. (2015). Crisis, policy discourse, and major policy change: Exploring the role of subsystem polarization in nuclear energy policymaking. European Policy Analysis, 1(2), 3470.

Robins, N. and McDaniels, J. (2016). The United Kingdom: Local Hub, Global Dynamics. UNEP Inquiry.

Schoenmaker, D. (2017). Investing For The Common Good: a sustainable finance framework. Bruegel.

Seabrooke, L. (2014). Epistemic arbitrage: Transnational professional knowledge in action. Journal of Professions and Organization, 1(1), 49-64.

Shwed, U., \& Bearman, P. S. (2010). The Temporal Structure of Scientific Consensus Formation. American Sociological Review, 75(6), 817-840.

Simms, A. (2001). An Environmental War Economy: The lessons of ecological debt and global warming. A New Economics Foundation pocket book.

Sparkes, R. (2002). Socially Responsible Investment: A Global Revolution. Chicester: JohnWiley

Thistlethwaite, J. (2011). Counting the Environment: The Environmental Implications of International Accounting Standards. Global Environmental Politics, 11(2), 75-97.

Thistlethwaite, J. (2015). The Challenges of Counting Climate Change Risks in Financial Markets. Centre for International Governance Innovation.

Thistlethwaite, J. (2017). Accounting-NGO Professional Networks: Issue Control over Environmental, Social and Governance Reporting. In Seabrooke, L. \& Henriksen, L. F. (Eds.), Professional Networks in Transnational Governance (101-114).

Thistlethwaite, J., \& Paterson, M. (2016). Private governance and accounting for sustainability networks. Environment and Planning C: Government and Policy, 34(7), 1197-1221.

Thistlethwaite, J., \& Wood, M. O. (2018). Insurance and Climate Change Risk Management: Rescaling to Look Beyond the Horizon. British Journal of Management, 29(2), 279-298.

Thomä, J., Dupré, S., Hayne, M., Weber, C., Hassan, F. \& Fulton, M. (2015). Assessing the Alignment of Portfolios with Climate Goals. $2^{\circ}$ investing initiative.

UNEP Inquiry (2015). The Financial System We Need: Aligning the Financial System with Sustainable Development. 
UNEP Inquiry (2016). The Financial System We Need: From Momentum to Transformation.

UNFCCC (2009). Report of the Conference of the Parties on its fifteenth session, held in Copenhagen from 7 to 19 December 2009. FCCC/CP/2009/11/Add.1.

Van Gelder, W., Herder, A. \& Kouwenhoven, D. (2010). Close the Gap: Benchmarking Credit Policies of International Banks. Bank Track \& Profundo.

Young, K. L., Marple, T., \& Heilman, J. (2017). Beyond the revolving door: Advocacy behavior and social distance to financial regulators. Business \& Politics, 19(2), 327-364.

Zadek, S. \& Robins, N. (2018). Making Waves: Aligning the Financial System with Sustainable Development. UNEP Inquiry. 
